\title{
Efficacy of the heater probe in peptic ulcer with a non-bleeding visible vessel. A controlled, randomised study
}

\author{
J L Jaramillo, C Carmona, C Gálvez, M de la Mata, G Miño
}

\begin{abstract}
A controlled, randomised study was performed to evaluate the efficacy of treatment with heater probe in the prevention of rebleeding from peptic ulcer with a non-bleeding visible vessel. One hundred and one patients were randomised into two groups: patients to be treated by heater probe $(n=51)$ and controls without active treatment $(n=50)$. In the heater probe group rebleeding occurred in five patients $(10 \%) v 13(26 \%)$ in the control group $(p=0.03)$, with a comparative risk of 0.38 in favour of the heater probe group. The difference in proportions of successful treatment for each group was $16 \cdot 2 \%$ in favour of the heater probe $(95 \% \mathrm{CI}=2$ to $31 \%)$. Haemorrhage directly related to heater probe treatment occurred in four patients. In three of them bleeding was easily controlled by further heater probe pulses. There were no other complications and no death in the heater probe group. One patient in the control group died of pulmonary embolism. No significant differences in the length of stay in hospital, blood transfusions, surgical rates, or death were found; the design of the study, however, precluded an adequate assessment of these variables, because the heater probe was an optional rescue treatment when high surgical risk patients rebled. These results suggest that the heater probe is an effective and safe procedure in the prevention of recurrent haemorrhage in peptic ulcer with a non-bleeding visible vessel. (Gut 1993; 34: 1502-1506)
\end{abstract}

Bleeding from peptic ulcer persists or recurs early in $25 \%$ of cases, ${ }^{1}$ which carries a high death rate related to the severity of bleeding or the need for surgical treatment. Endoscopic stigmata of recent haemorrhage allow the identification of lesions with a high risk of rebleeding. A nonbleeding visible vessel located in the crater of the ulcer has a $30-50 \%$ probability of recurrence..$^{2-6}$ Therapeutic endoscopy with electrocoagulation, photocoagulation, or injection of sclerosant or vasoactive substances, has been effective in: (a) stopping active haemorrhage, ${ }^{37-11}$ (b) diminishing the rebleeding rate, ${ }^{3467-19}$ (c) reducing the need of surgery, 48-10141617 and (d) decreasing the death rate.$^{81017}$ These results, however, are not uniform. ${ }^{20-23}$

Heater probe treatment of bleeding ulcer may be better than sclerosis with alcohol for stopping acute haemorrhage. ${ }^{24}$ Heater probe may be less effective, however, than epinephrine injection in the initial control of active haemorrhage. ${ }^{25}$ Heater probe is not superior to YAG laser or bipolar electrocoagulation in the immediate control of bleeding, decreasing the rebleeding rate, the need for surgery, or the death rate. ${ }^{626}$ Therefore, it remains to be proved whether the use of heater probe is better than no active treatment and a close observation of the patient. ${ }^{462728}$

The aim of this study is to evaluate the efficacy of the heater probe in preventing recurrence of haemorrhage from peptic ulcer with a nonbleeding visible vessel. A control group without active treatment allowed us to compare the results.

\section{Methods}

\section{PATIENTS}

Between November 1988 and December 1991 all consecutive patients who were bleeding and admitted to the gastroenterology unit were considered for this study. Patients were included if a gastric or duodenal peptic ulcer with a nonbleeding visible vessel was identified. The criteria for exclusion were: (a) active bleeding from the ulcer; (b) other coexistent lesions that could be the cause of bleeding; (c) malignant ulcers, and (d) patient refusal to heater probe treatment. Patients were separated according to ulcer location (gastric or duodenal) and then randomised into control and treatment groups. Randomisation was done with a table of random numbers, the allocation codes were introduced in two series of sealed envelopes according to stratification class. Patients were randomised at the time of endoscopy or within 12 hours after fulfilling the inclusion criteria. This study was approved by the ethical committee of the hospital.

\section{DIAGNOSIS}

Upper gastrointestinal bleeding was diagnosed only if haematemesis or melaenas, or both were confirmed by the hospital staff. The cause of bleeding was established by endoscopy within 12 hours of admission. To obtain a correct view of the ulcer and stigmata of recent bleeding, the lesions were gently washed to remove blood that had not adhered to the lesions.

TREATMENT

All patients in the study received the following treatment: ranitidine $50 \mathrm{mg}$ intravenously three times per day, volume replacement with intravenous fluids, and blood to maintain packed cell volume above $28 \%$. The control group did not 
receive endoscopy treatment and was studied closely. Patients in the heater probe group were treated according to the endoscopic procedure.

Endoscopic treatment - an Olympus HPU heater probe device with $3.2 \mathrm{~mm}$ and, occasionally, a $2.3 \mathrm{~mm}$ probe was used. The energy applied in each pulse was 25-30 joules. Pulses were given until the vessel had been flattened and turned dark. The treatment was only given by one of the two physicians participating in the study (JLJ and CG), both with previous experience in the use of heater probe. Coagulation was obtained by pressing in several points around and on the base of the vessel.

Rescue treatment - surgery was indicated in patients of each group if bleeding recurred. Surgical risk was evaluated on admission. Patients over 65 years suffering from a severe systemic condition were considered as high risk cases. In patients with severe haemorrhage and low surgical risk, surgical intervention was carried out immediately. Surgery was performed within 24 hours if the relapse was mild. High surgical risk patients without haemodynamic changes, had heater probe treatment and, if bleeding persisted or recurred, the patient was operated on.

\section{MONITORING}

Monitoring of the patients included recording of blood pressure, heart rate, and urine output and, in haemodynamically unstable patients, measurement of central venous pressure. Values of packed cell count, haemoglobin, urea, glucose, creatinine, and electrolytes were obtained at admission. These tests were repeated 12 hours after admission and every 24 hours thereafter. Packed cell volume and haemoglobin were also measured after each bleeding episode. Characteristics and quantity of vomit, gastric aspirate, and stools were recorded. A soapy enema was given daily to avoid accumulation of faeces.

END POINTS

Rebleeding, or if absent, discharge, or death were considered the end points of the study.

\section{DEFINITIONS}

Visible vessel - a raised red or black spot protruding on the ulcer crater that does not disappear with washing.

Limited haemorrhage - the presence of unchanged packed cell volume, haemodynamic stability, lack of haematemesis, no evidence of blood in the gastric aspirate, and normal stools or only traces of melaena.

Continued haemorrhage - (a) if the volume of intravenous fluids required to restore or maintain haemodynamic stability was greater than $1000 \mathrm{ml} /$ hour or $3000 \mathrm{ml} / 12$ hours, (b) fresh haematemesis and, (c) haematemesis or melaenas in association with a fall in packed cell volume greater than $5 \%$ in a 24 hour period, two days after admission.

Rebleeding - bloody gastric aspirate, haematemesis or melaenas while in the hospital, after initial control of bleeding, and the stools had become normal.

Haemodynamic stability - presence of all of the following, (a) systolic blood pressure greater than $100 \mathrm{~mm} \mathrm{Hg}$, (b) heart rate less than 100 beats/min, (c) urine output greater than 35 $\mathrm{ml} /$ hour and, (d) no signs or symptoms of impaired systemic perfusion.

\section{ASSESSMENT}

The efficacy of the heater probe was assessed with the results obtained at the first attempt. Data recording and assessment of results were carried out by a member of the unit who did not participate in endoscopic treatment or looked after the patients. The proportion of rebleeding in the heater group was compared with that in the control group. An intention to treat analysis was carried out.

\section{STATISTICS}

Sample size was calculated assuming $30 \%$ and $10 \%$ rebleeding rate in the control and treated groups, respectively, ${ }^{2}$ and by giving values of 0.05 to an $\alpha$ error and 0.2 to $\beta$ error. After calculation the number obtained was 48 in each group and 5\% was added to compensate for nonevaluable patients. Thus, the total number including both groups was 101 .

Fisher's exact test or $\chi^{2}$ test with Yates's correction were used, where appropriate, to compare proportions and Student's $t$ test was used for continuous variables. Confidence intervals and relative risk were also calculated.

\section{Results}

One hundred and one patients were included in the study. Thirty five had bleeding gastric ulcer and sixty six a duodenal ulcer. After randomisation 51 patients were included in the heater probe group and 50 in the control group. Table I shows the clinical data on admission.

In the heater probe group, coagulation was achieved in 49 patients. The two patients in whom coagulation was not achieved had ulcers located in the inferior and posterior wall of the duodenal bulb, respectively. The approach to the visible vessel was difficult in 10 patients. The probe was applied from the front in 32 and laterally in 17 cases. A mean of 8.4 pulses and 211 joules, were used in each patient, with the $2 \cdot 3$ $\mathrm{mm}$ probe in four cases and $3.2 \mathrm{~mm}$ probe in the remainder. Four patients bled during the procedure. In three of them, bleeding was finally controlled during the same session. The fourth patient required local epinephrine injection in addition to repeated heater probe pulses and was considered a failure in the final statistical analysis. In four additional patients bleeding recurred after heater probe treatment and in one of them, with high surgical risk, successful control of haemorrhage was obtained in a second thermocoagulation session. The remaining three patients required operations. In one of these three patients the bleeding started in another ulcer not seen during the first endoscopy and therefore not treated with heater probe. Thus, 
TABLE I Characteristics of patients entered into the study

\begin{tabular}{|c|c|c|c|}
\hline & $\begin{array}{l}\text { Heater probe } \\
(n=51)\end{array}$ & $\begin{array}{l}\text { Control } \\
(n=50)\end{array}$ & $p$ \\
\hline \multicolumn{4}{|l|}{ Sex: } \\
\hline Men & 32 & 35 & \\
\hline Women & 19 & & NS \\
\hline Age (x (SD)) & $56 \cdot 7(17)$ & $57 \cdot 2(14)$ & NS \\
\hline Associated disease & 19 & 12 & NS \\
\hline High risk surgical patients & 12 & 8 & NS \\
\hline \multicolumn{4}{|l|}{ Ulcer location: } \\
\hline Gastric & 17 & 18 & NS \\
\hline \multirow{2}{*}{\multicolumn{4}{|c|}{ Initial symptoms: }} \\
\hline & & & \\
\hline Melaena only & 32 & $\begin{array}{l}23 \\
27\end{array}$ & NS \\
\hline \multicolumn{4}{|l|}{ Haemodynamics at admission. } \\
\hline Pulse rate $(\mathbf{x}(\mathrm{SD}))$ & $\begin{array}{r}89(18) \\
127(23)\end{array}$ & $\begin{array}{r}89(15) \\
123(25)\end{array}$ & $\begin{array}{l}\text { NS } \\
\text { NS }\end{array}$ \\
\hline Shock & 4 & 7 & NS \\
\hline $\begin{array}{l}\text { Packed cell volume }<30 \text { at } \\
\text { admission }\end{array}$ & 18 & 11 & NS \\
\hline
\end{tabular}

$\mathrm{SBP}=$ systolic blood pressure; $\mathrm{NS}=\mathrm{p}>0.05$.

the number of rebleeding cases in the group with heater probe treatment was five $(9 \cdot 8 \%)$, two from gastric and three from duodenal ulcers. Patients received a mean of $1.2 \mathrm{U}$ of packed red blood cells $(\mathrm{SD}=2)$ and they were in hospital during a mean period of $7 \cdot 4$ days $(S D=3 \cdot 6$ ) (Tables II and III). There were no deaths in this group.

In the control group, bleeding recurred in 13 patients $(26 \%)$, six with gastric ulcers and seven with ulcer located in the duodenum. Five were poor subjects for operation, so that endoscopic treatment by heater probe was performed. Two patients required operation because of further recurrence after heater probe treatment and difficulties in reaching the lesion, respectively. In the other five rebleeding patients an operation was performed successfully. Medical treatment was considered only for the remaining three patients. Two had a mild haemorrhage and the third patient refused both operation and heater probe treatment. This patient required six packed red cells units before the bleeding

TABLE II Treatment data

\begin{tabular}{lll}
\hline & Heater probe & Control \\
\hline Randomised patients & 51 & 50 \\
Thermocoagulation & 49 & - \\
Rebleeding & 5 & 13 \\
$\quad$ Rescue treatment: & 1 & 3 \\
$\quad$ Heater probe only & 1 & - \\
$\quad$ Heater probe+epinephrine & - & 1 \\
$\quad$ Heater probe+ surgery & 3 & 6 \\
$\quad$ Surgery only & - & 3 \\
$\quad$ Medical only & $1 \cdot 2(2)$ & $2(2 \cdot 5)$ \\
Transfusion: & &
\end{tabular}

TABLE III Outcome of patients in heater probe and control groups

\begin{tabular}{lll}
\hline & $\begin{array}{l}\text { Heater probe } \\
(n=51)\end{array}$ & $\begin{array}{l}\text { Control } \\
(n=50)\end{array}$ \\
\hline $\begin{array}{l}\text { Rebleeding complication: } \\
\text { Induced bleeding } \\
\quad \text { Controlled by heater probe }\end{array}$ & 5 & $13^{\star}$ \\
$\quad 3$ & - \\
$\begin{array}{l}\text { Uncontrolled } \\
\text { Pulmonary embolism }\end{array}$ & 1 & \\
$\begin{array}{l}\text { Emergency surgery } \\
\text { Stay in hospital (days): } \\
\text { Mean (SD) } \\
\text { Median (IQR) }\end{array}$ & 3 & 1 \\
Death & $7 \cdot 4(3 \cdot 6)$ & $7 \cdot 7(4 \cdot 4)$ \\
\hline
\end{tabular}

^: $p=0.03$ (Fisher's exact test); $\mathrm{IQR}=$ interquartile range. stopped. One patient died because of pulmonary embolism during the postoperative period. An average of $2(\mathrm{SD}=2.5) \mathrm{U}$ of packed red cells were transfused in each patient and required $7 \cdot 7$ $(\mathrm{SD}=4 \cdot 4)$ days' stay in hospital (Tables II and III).

The incidence of rebleeding was lower in the heater probe treated patients than in the control group (Fisher's exact test $p=0.03$ ) with a comparative risk of $0.38(95 \% \mathrm{CI} 0 \cdot 14$ to 0.98$)$. The difference in proportions of successful treatment in each group was $16.2 \%$ in favour of heater probe, with a $95 \%$ CI ranging from $2 \%$ to $31 \%$. There were no significant differences between both groups in death, transfusion requirements, and days needed in hospital.

When the adherence to treatment is considered, the data analysis results are very similar to those seen in the intention to treat analysis $(10.2 \%$ and $26 \%$ of recurrences in heater probe and in control group respectively; Fisher's exact test $p=0 \cdot 04)$. Analysis of results according to location of the ulcer showed a tendency in favour of the heater probe in both gastric and duodenal sites, but statistical significance was not reached because of the small size of subgroups.

\section{Discussion}

This study shows that treatment of bleeding ulcers with heater probe reduces the rebleeding rate compared with medical conservative management. The heater probe reached a visible vessel in $90 \%$ of the patients. The two patients in whom the lesion was not reached had ulcers located in the inferior and posterior wall of duodenal bulb. The treatment was satisfactorily performed in all patients despite some difficulties in reaching the lesion in $20 \%$ of them. In the group of patients treated with the heater probe the incidence of rebleeding was about one third of that in the control group. There was no death in the endoscopy treated group. The only complication in this group was an uncontrolled haemorrhage induced by probe manipulation. The blood transfusion requirements were similar in both groups. Differences in days spent in hospital, however, amount of blood transfused, and operations required, are difficult to analyse because heater probe was an option for rescue treatment in the control group. Endoscopic treatment has been shown to be beneficial in bleeding patients. ${ }^{111}$ Thus heater probe treatment was considered an option for rescue treatment in high risk patients. This decision was made based on ethical consideration despite the fact that the use of the heater probe as a rescue treatment would be a confounding variable in the assessment of the subsequent outcome (operation or death). Nevertheless, this strategy did not affect the results at the end point established in the methods (rebleeding).

It should be pointed out that in our control group, the incidence of rebleeding was $26 \%$, which is less than the 30 to $50 \%$ seen by others. ${ }^{2+6}$ Our definition of visible vessel is widely accepted. ${ }^{29}{ }^{30}$ The endoscopic concept of visible vessel includes several stages of the same lesion and even various types of lesions. It is interesting also that slight changes in the colour 
of the so called visible vessel are associated with a different risk of rebleeding ranging from 18 to $50 \% .^{230-32}$

In uncontrolled studies, the use of heater probe in active bleeding ulcers or in ulcers with stigmata of recent haemorrhage, achieves haemostasis in 75 to $100 \%$ of cases, and in 69 to $86 \%$ of patients the control of bleeding is definitive. ${ }^{33-36}$ Randomised controlled trials have shown similar results. Compared with other endoscopic treatment used to stop bleeding, the heater probe seems better than pure alcohol sclerosis $^{4}$ but less effective than epinephrine injections..$^{25}$ No significant difference was seen when compared with laser YAG or bipolar electrocoagulation. ${ }^{6246}$ With the heater probe the complication rate was less than $5 \% .^{625} 27$ Difficulties in reaching the bleeding point have been reported in $20 \%$ of cases. ${ }^{25}$ Thus, because of inaccessibility two to nine per cent of ulcers were excluded from randomisation. ${ }^{624}$ Ulcers located in the posterior or lower walls of the duodenal bulb and in the upper portion of the lesser curvature of the stomach are the most difficult to reach. ${ }^{24263738}$ Problems in gaining access to lesion must be taken into account in the final evaluation of any of the endoscopic types of treatment. The current data are insufficient to establish the suitability of the heater probe compared with other types of endoscopic treatment.

Previous studies have not shown that the heater probe is less effective than other types of endoscopic treatment, whose efficacy is already proved. ${ }^{10}$ "Although the benefit of the heater probe $v$ medical treatment alone has not been established, it seems more effective. There are only two studies published in complete form in which the results showed statistical difference. Fullarton $e t a l^{27}$ obtained definitive haemostasis in $20(100 \%)$ of the treated patients $v 22 \%$ failures in the control group $(p=0.05)$. Lin et al, ${ }^{4}$ after one or two sessions of thermocoagulation, achieved a significant lower rate of rebleeding, emergency operation, death, and days in hospital compared with control patients. In a third study ${ }^{5}$ in ulcers with a non-bleeding visible vessel, heater probe treatment did not improve significantly the rebleeding or death rates compared with controls. Finally, the results of Matthewson et $a l^{6}$ suggest that the heater probe has some advantages over conservative treatment in preventing rebleeding and decreasing the number of operations. The analysis of the results, however, did not show a statistical difference. Nevertheless, these two last studies ${ }^{5}$ cannot exclude a real benefit for the heater probe. In the Matthewson trial with a comparative risk or rebleeding of 0.82 in treated $v$ control patients the $\beta$ error probability was 0.54 . In the report by Lin et al, the comparative risk was 0.56 and the $\beta$-error 0.29 . In these two studies the statistical power is lower than the conventional $80 \%$ required to reject a true effectiveness with statistical confidence. In addition, the results of two different studies have been published in abstract form, ${ }^{289}$ one of these claiming a therapeutic benefit for heater probe. ${ }^{28}$

This study, including estimation of sample size and the methods used, was aimed at avoiding problems with statistical evaluation of the results. The inaccessible lesions were included in the final analysis as the aim was to evaluate this procedure according to the intention to treat. Only the results from the first treatment with the heater probe were included in the statistical analysis although a definitive control of the bleeding was achieved sometimes after additional sessions. Finally, rebleeding from a previously missed and non-treated ulcer was considered a failure.

A meta analysis including our data and data obtained from previous publications ${ }^{462739}$ was performed to further evaluate the effectiveness of the heater probe, according to the DerSimonian-Laird method in rates differences estimation and the Mantel-Haenszel-Peto method by odds ratio. ${ }^{40}$ The results of the meta analysis suggest that the heater probe is useful in the treatment of bleeding ulcers. The combined total number of patients included in the above mentioned studies is 428, 220 treated and 208 in the control group. The mean rate of recurrent or continued bleeding in control groups was $37 \%$. In the heater probe group the incidence of bleeding was lowered to $14 \%$ (pooled rate difference $95 \% \mathrm{CI}=-0.23(0.08)$ ) and the typical odds ratio of uncontrolled haemorrhage was 0.29 (95\% $\mathrm{CI}=0.19$ to 0.45 ) favouring the heater probe. In ulcers with a non-bleeding visible vessel, the mean rate of rebleeding was $33 \%$ in control groups, the reduction as a result of treatment $19 \%$ (pooled rate difference $95 \%$ $\mathrm{CI}=0.19(0.09))$ and the odds ratio $0.37(95 \%$ $\mathrm{CI}=0 \cdot 21$ to $0 \cdot 65$ ).

In summary, this study shows that compared with medical treatment the heater probe reduces the rebleeding rate in a non-bleeding visible vessel by $62 \%$, there was no death, and complications were minimal. Our results suggest that heater probe is an effective and safe procedure in the prevention of recurrent haemorrhage in peptic ulcer with a non-bleeding visible vessel.

This study was supported by grant no $90 / 0474$ FISss

1 Morgan AG, Clamp SE. OMGE International Upper Gastrointestinal Bleeding Survey, 1978-1986. Scand $f$ Gastroenterol 1988; 23 (suppl 144): 51-8.

2 Wara P. Endoscopic prediction on major rebleeding. A prospective study stigmata of hemorrhage in bleeding ulcer. Gastroenterology 1985; 88: 1209-14.

3 Swain CP, Kirkham JS, Salmon PR, Bown SG, Northfield T. Controlled trial of Nd-YAG laser photocoagulation in Controlled trial of Nd-YAG laser photoco
bleeding peptic ulcer. Lancet 1986; i: 1113-6.

4 Lin HJ, Lee FY, Kang WM, Tsai YT, Lee SD, Lee CH. Heat probe thermocoagulation and pure alcohol injection in massive peptic ulcer haemorrhage: a prospective, randomised controlled trial. Gut 1990; 31: 753-7.

5 Lin HJ, Lee FY, Kang WM, Tsai YT, Lee SD, Lee CH. A controlled study of therapeutic endoscopy for peptic ulcer with non-bleeding visible vessel. Gastrointest Endosc 1990 36: 241-6.

6 Matthewson K, Swain CP, Bland M, Kirkham JS, Bown SG, Northfield TC. Randomized comparison of Nd-YAG laser, heater probe, and no endoscopic therapy for bleeding peptic heater probe, and no endoscopic therapy for
ulcers. Gastroenterology 1990; 98: 1239-44.

7 Rutgeerts P, Vantrappen G, Broeckaert L, Janssens J, Coremans G, Geboes K, et al. Controlled trial of YAG laser treatment of upper digestive hemorrhage. Gastroenterology treatment of upper

8 Salmon PR, Swain CP. Laser photocoagulation. Results of a randomised controlled trial. Endoscopy 1986; 18 (suppl 2): 56-7.

9 Laine L. Multipolar electrocoagulation in the treatment of active upper gastrointestinal tract hemorrhage. $N$ Eng F Med 1987; 316: 1613-7.

10 Sacks HS, Chalmers TC, Blum AL, Berrier J, Pagano D. Endoscopic hemostasis. An effective therapy for bleeding peptic ulcers. $\mathscr{F} A M A$ 1990; 264: 494-9.

11 Naveau S, Perrier C, Mory B, Poinard T, Chaput JC. Hémostase endoscopique des hémorragies ulcéreuses gastroduodenales. Gastroenterol Clin Biol 1991; 15: 580-97. 
12 O'Brien JD, Day SJ, Burnham WR. Controlled trial of small bipolar probe in bleeding peptic ulcer. Lancet 1986 ; i: 464-7. 3 Moretó M, Zaballa M, Ibañez S, Setien F, Figa M. Efficacy of monopolar electrocoagulation in the treatment of bleeding gastric ulcer: a controlled trial. Endoscopy 1987; 19: 54-6.

14 Panés J, Viver J, Forné M, García-Olivares E, Marco C, Garau $\mathrm{J}$. Controlled trial of endoscopic sclerosis in bleeding peptic ulcers. Lancet 1987; ii: 1292-4.

15 Balanzó J, Sainz S, Such J, Espinos JC, Guarner C, Cusso X, et al. Endoscopic hemostasis by local injection of epinephrine and polidocanol in bleeding ulcer. A prospective randomized trial. Endoscopy 1988; 20: 289-91.

16 Laine L. Multipolar electrocoagulation in the treatment of peptic ulcer with nonbleeding visible vessel. Ann Intern Med
$1989 ; 110: 510-4$.

17 Pascu O, Dräghici A, Acalovchi I. The effect of endoscopic hemostasis with alcohol on the mortality rate of nonvariceal upper gastrointestinal hemorrhage. A randomized prospective study. Endoscopy 1989; 21: 53-5.

18 Rutgeerts P, Vantrappen G, Broeckaert L, Coremans G Janssens J, Hiele M. Comparison of endoscopic polidocanol injection and YAG laser therapy for bleeding peptic ulcer. Lancet 1989; i: 1164-7.

19 Rajgopel C, Palmer KR. Endoscopic injection sclerosis: effective treatment for bleeding peptic ulcer. Gut 1991; 32 727-9.

20 Valon AG, Cotton PB, Laurence BH, Armengol Miro JR, Salord Oses JC. Randomised trial of endoscopic argon laser photocoagulation in bleeding peptic ulcers. Gut 1981; 22. 228-33.

21 Kernoan RM, Anderson JR, McKelvey STD, Kennedy TL. A controlled trial of bipolar electrocoagulation in patients with

22 Brearley S, Hawker PC, Dykes PW, Keighley MRB. Perendoscopic bipolar diatermy coagulation of visible vessels using a $3.2 \mathrm{~mm}$ probe. A randomised clinical trial. Endoscopy 1987 19: $160-3$

23 Krejs GJ, Little KH, Westergaard H, Hamilton JK, Polte DE. Laser photocoagulation for the treatment of acute peptic-ulcer bleeding. A randomized controlled clinical trial. N Engl f Med 1987; 316: 1618-21.

24 Lin HJ, Tsai YT, Lee SD, Lai KH, Lee FY, Lin CY, et al. A prospective randomized trial of heat probe thermocoagulation versus pure alcohol injection in nonvariceal peptic ulcer hemorrhage. Am $\mathcal{F}$ Gastroenterol 1988; 83: 283-6.

25 Chung SCS, Leung JWC, Sung JY, Lo KK, Li AKC Injection or heat probe for bleeding ulcer. Gastroenterolog 1991; 100: 33-7.

26 Hui WM, Ng MMT, Lok ASF, Lai CL, Lau YN, Lam SK. A randomized comparative study of laser photocoagulation, heater probe, and bipolar electrocoagulation in the treatment of actively bleeding ulcers. Gastrointest Endosc 1991; 37: 299-304.

27 Fullarton GM, Birnie GG, Macdonald A, Murray WR. Controlled trial of heater probe treatment in bleeding peptic ulcers. Br $\mathcal{F}$ Surg 1989; 76: 541-4.

28 Jensen DM, Machicado GA, Kovacs TOG, Van Deventer G, Randall GM, Reedy T, et al. Controlled, randomized study of heater probe and BICAP for hemostasis of severe ulcer bleeding. Gastroenterology 1988; 94: A208.

29 Morgan AG, Clamp SE. OMGE. International Upper Gastrointestinal Bleeding Survey 1978-1982. Scand f Gastroenterol 1984; 19 (suppl 95): 41-58.

30 Swain CP, Storey DW, Bown SG, Heath J, Mills TN, Salmon PR, et al. Nature of the bleeding vessel in recurrently bR, et al. Nature of the bleeding vessel in recurrently

31 Johnston JH. Endoscopic risk factors for bleeding peptic ulcer. Gastrointest Endosc 1990; 36: S16-20.

32 Papp JP. The visible vessel. Am $\mathcal{f}$ Gastroenterol 1991; 86: 401-2.

33 Shorvon PJ, Leung JWC, Cotton PB. Preliminary clinical experience with the heat probe at endoscopy in acute upper gastrointestinal bleeding. Gastrointest Endosc 1985; 31: $364-6$.

34 Lin HJ, Tsai YT, Lee SD, Lai KH, Lee FY, Lin CY, et al. Heater probe in massive peptic ulcer hemorrhage and shock. 7 Clin Gastroenterol 1988; 10: 623-6.

35 Lin HJ, Tsai YT, Lee SD, Lai KH, Lee CH. Heat probe therapy for severe hemorrhage from a peptic ulcer with a visible vessel. Endoscopy 1988; 20: 131-3.

36 Lin HJ, Lee FY, Chan CY, Huang ZC, Kang WM, Lee CH, et al. Heat probe thermocoagulation as a substitute for surgical intervention to arrest massive peptic ulcer hemorrhage: an experience in 153 cases. Surgery 1990; 108: 18-21.

37 Johnston JH, Sones JQ, Long BW, Posey EL. Comparison of heater probe and YAG laser in endoscopic treatment of major bleeding from peptic ulcers. Gastrointest Endosc 1985; 31: $175-80$.

38 Consensus statement of therapeutic endoscopy and bleeding ulcers. Gastrointest Endosc 1990; 26: S62-5.

39 Avgerinos A, Rekoumis G, Argirakis G, Gouma P, Papadimitriou N, Karamanolis D. Randomizad comparison of endoscopic heater probe electrocoagulation (HP), injection of adrenalin (IA) and no endoscopic therapy (C) for injection of adrenalin (IA) and no endoscopic therapy (C)

40 Chalmer TC, Buyse ME. Meta-analysis. In: Chalmer TC, ed Data analysis for clinical medicine. Rome: International Data analysis for clinical medic
University Press, 1988: 74-84. 